\title{
Use of VOC sensors for air quality control of building ventilation systems
}

\author{
M. Großklos \\ Institut Wohnen und Umwelt, Darmstadt, Germany \\ Correspondence to: M. Großklos (m.grossklos@iwu.de)
}

Received: 29 October 2014 - Revised: 26 March 2015 - Accepted: 7 April 2015 - Published: 8 May 2015

\begin{abstract}
Air quality control with VOC (volatile organic compound) sensors in residential buildings could increase user comfort by adapting to the actual contaminant level. Preliminary tests assessed the dynamics of VOC levels in single-family passive houses with a ventilation system. At normal and exceptional usages, sufficient signal variations were measured for air quality control. An air quality control was developed and tested in four single-family passive house dwellings to control the building ventilation system via VOC sensors and a special adaptation algorithm to handle variable contaminant loads and sensor drift. Results showed good operation of the air quality control for the ventilation system, detecting changing contaminants within a few minutes and changing the air flow rate in the building immediately. The 43 VOC sensors used during the monitoring had more than 1.2 million working hours in total without any electrical failure, but with a loss of sensitivity for the calibration gas CO. The air quality control could manage that loss of sensitivity and worked well till the end of the field test. A comparison between $\mathrm{VOC}$ and $\mathrm{CO}_{2}$ sensors in one building resulted in more detailed information about emission rates in the room with the VOC sensor, allowing one to get a better reaction of the ventilation system.
\end{abstract}

\section{Introduction}

Mechanical ventilation systems with heat recovery could reduce energy consumption and increase residents' comfort level at the same time. Ventilation systems in highly efficient residential passive houses are normally controlled by hand or by a time program. But, the individual habits of people could rarely be defined in fixed programs because there are times with low contaminants in the room air when nobody is there and other times with peak contaminants because of additional people or odors from the kitchen or the bathroom. The ventilation system normally could not manage those variable loads automatically. The residents have to interact with the control system to optimize the air quality and the energy consumption permanently. Especially at night, when residents are sleeping, manual interaction with the ventilation system is not feasible. The advantages of sensor-based demand-controlled ventilation systems to increase user comfort have been known for a long time, but only a few studies were published about the way to implement an air quality ventilation control and the usage of VOC (volatile organic compound) sensors (Fisk et al., 1998).
During a research project, an automatic air quality control was developed for ventilation systems to deal with these dynamic changes in air quality in residential buildings using VOC sensors. In a second project phase, the air quality control was tested in four single-family passive houses over a minimum time of 2 years (one building for nearly 4 years) to observe how the system works in practice. Results are presented in this paper.

\subsection{Project aims and activities}

The project contained a theoretical survey of the possibilities using VOC sensors in residential buildings, including first measurements in passive houses to distinguish the signal dynamic in residential applications. The second phase was a field test over a minimum period of 2 years to prove the function of the new air quality ventilation control.

Additional topics like detecting the opening stage of the windows using the ventilation system or a dynamic user feedback of their window opening behavior will not be discussed in this paper. The project started in 2006 and was finished in 


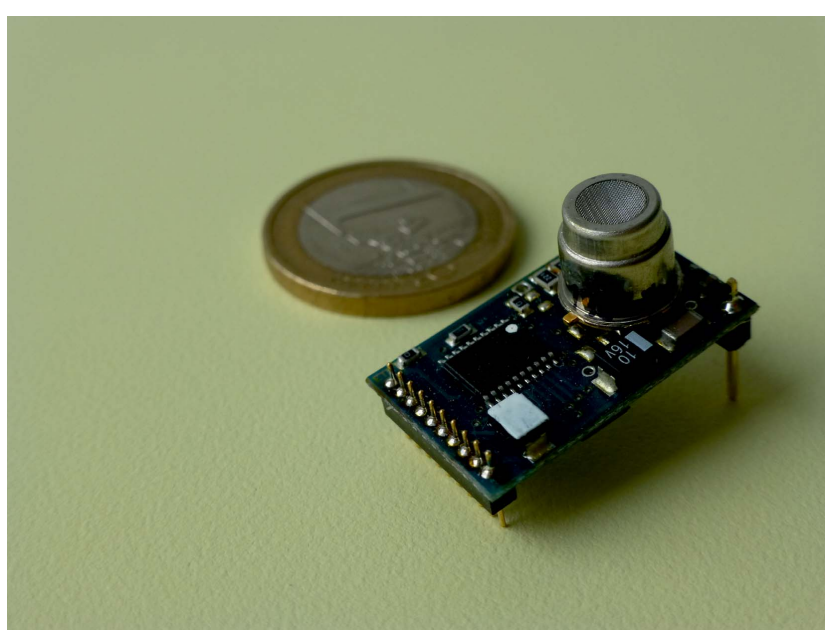

Figure 1. The VOC sensor manufactured by the former ETRElectronic.

2012. The results were published in three reports (Großklos et al., 2011, 2012; Knissel et al., 2011).

\subsection{The VOC sensors}

For the field test, 43 VOC sensors in total (Fig. 1), manufactured by former company ETR-Electronic in Dortmund, Germany, were placed in the buildings. The sensors are tin oxide sensors on a ceramic substrate using LuQaS technology (see FIA e.V., 2005). This means that the sensor temperature is varied between 300 and $400^{\circ} \mathrm{C}$ dynamically to detect broadband oxidable gases and to reduce the influence of air humidity. The measuring range is between $<10$ and $15000 \mathrm{ppm}$ as a sum of all different VOC components. For carbon monoxide, which is used for calibration, the maximum measurable concentration is about $34 \mathrm{ppm}$. The sensor signal is transmitted as an integer value between 80 and 254 digits (measured values in normal unpolluted room air start at 100-120 digits), so there is no conversion to known references or thresholds. Because the sensor output is nearly logarithmic, Eq. (1) is used for linearization:

$C_{\text {Lin }}=\left(\frac{C_{\text {Digits }}}{41.4}-1.57\right)^{2.34}$.

To reduce the influence of the casing, the sensors were mounted in small boxes made out of stainless steel.

\section{Preliminary tests}

Before using the sensors for building ventilation control, it was not clear whether the dynamics of the measured concentration in the exhaust air is sufficient for the control system. Numerous tests were done to characterize the behavior and signal amplitudes in ventilated single-family homes with lower emission rates than in office buildings or in schools, which were tested in other publications (e.g., Kopiske et al., 2004). Additionally, the repeatability and the time-dependent drift between the sensors in room air was tested. Finally, the measurement of outside air VOC signals at different places within a particular region was tested.

\subsection{VOC sensor in a passive house sleeping room compared to exhaust air of the ventilation system}

Figure 2 shows the measurement of the VOC and $\mathrm{CO}_{2}$ values in a passive house bedroom over 2 days. At the beginning of the period shown, the flow rate of the ventilation system was slightly reduced to $86 \%$ compared with the design flow rate (to simulate pollution of the filters). During the first day, the VOC levels in the bedroom and the exhaust air were quite constant, but on a different level. The $\mathrm{CO}_{2}$ level in the bedroom began to rise in the evening because of open doors in the building. When the bedroom was occupied at about 11 p.m. in the evening, $\mathrm{VOC}$ and $\mathrm{CO}_{2} \mathrm{lev}$ els increased significantly. The dynamics of the VOC signal was up to $50 \%$ (based on a signal range of the VOC sensor of between 80 and 254 digits). Relative humidity (rh) varied only little around a mean value of $43.7 \%$ rh (standard deviation $1.58 \% \mathrm{rh}$ ), so an influence on the sensor signal is not likely. Additional chemical analyses were not executed. During the night, the door of the bedroom was then opened, and an additional passive air exchange to the stairway occurred. The VOC level as well as the $\mathrm{CO}_{2}$ concentration lowered directly. In the morning, when the occupants left the bedroom, there was an exponential decline in the concentration of both, $\mathrm{VOC}$ and $\mathrm{CO}_{2}$, in the room.

Interesting for the ventilation control are the VOC levels of the exhaust air. At the beginning, it stayed on a quite constant level and then increased clearly in the evening when two persons were in the building. The moving of the users from the living room to the bedroom has limited influence on the VOC level in the exhaust air. The VOC peaks in the bedroom could also be found in the exhaust air. Additionally, there are peaks, for example, when the residents were showering. The signal dynamics between daytime and night is about $20 \%$. That means that there is sufficient variation for an air quality ventilation control.

\subsection{Vertical sensor position and relative sensor drift}

The influence of the vertical sensor position was tested in an office room with three sensors: directly at the floor, at $1 \mathrm{~m}$ height at the desk and at $2.20 \mathrm{~m}$ above the floor. Figure 3 shows that the measured VOC values at 0 and $1 \mathrm{~m}$ are very similar and have a comparable dynamic. The sensor at $2.20 \mathrm{~m}$ height has a slightly higher variation and a signal between 2 and 3 digits higher than at floor level. Before that test, all three sensors had been in permanent operation for 3 weeks at the same place, and the results at 0 and $2.20 \mathrm{~m}$ were calibrated onto the difference in the level of the sensor 


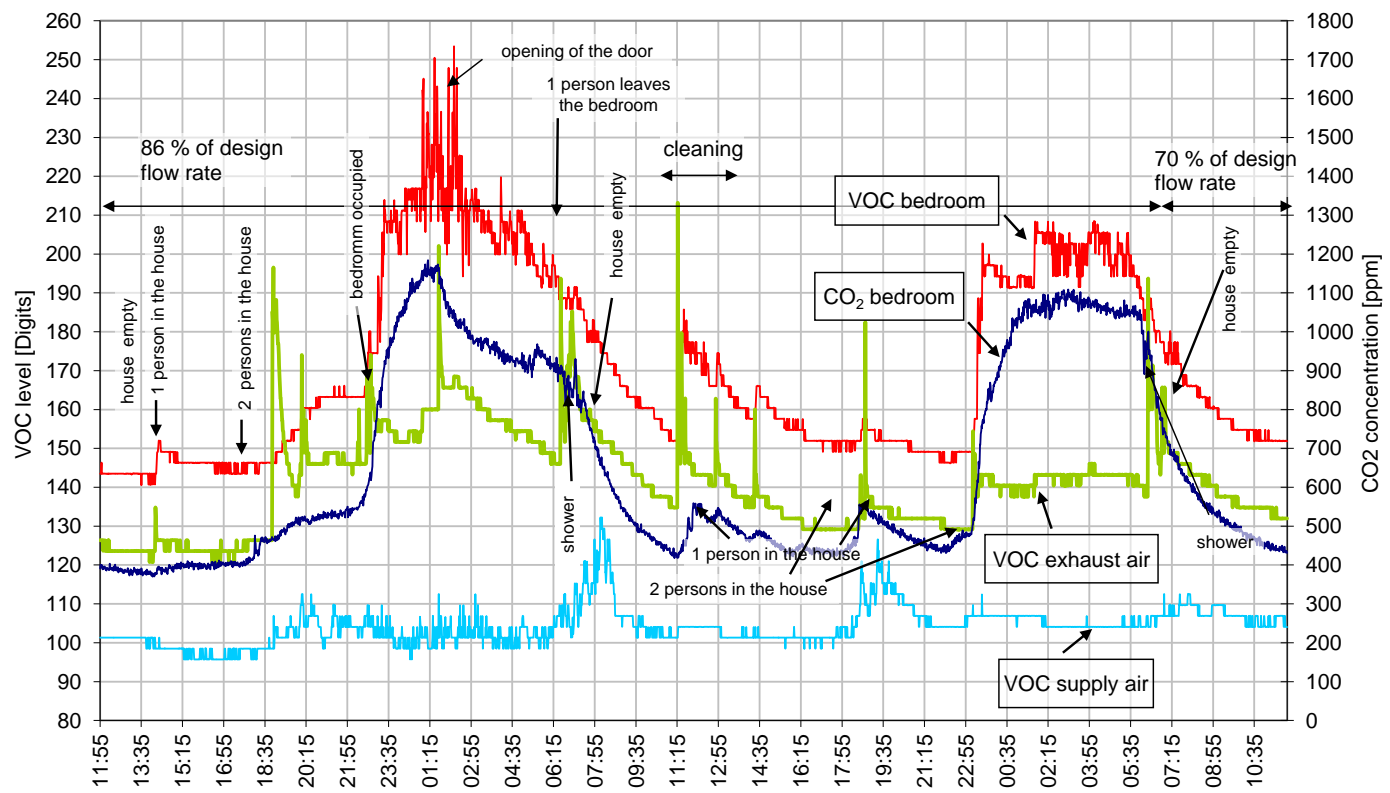

Figure 2. Measurements of $\mathrm{VOC}$ and $\mathrm{CO}_{2}$ in room air and exhaust air in a passive house bedroom over 2 days.

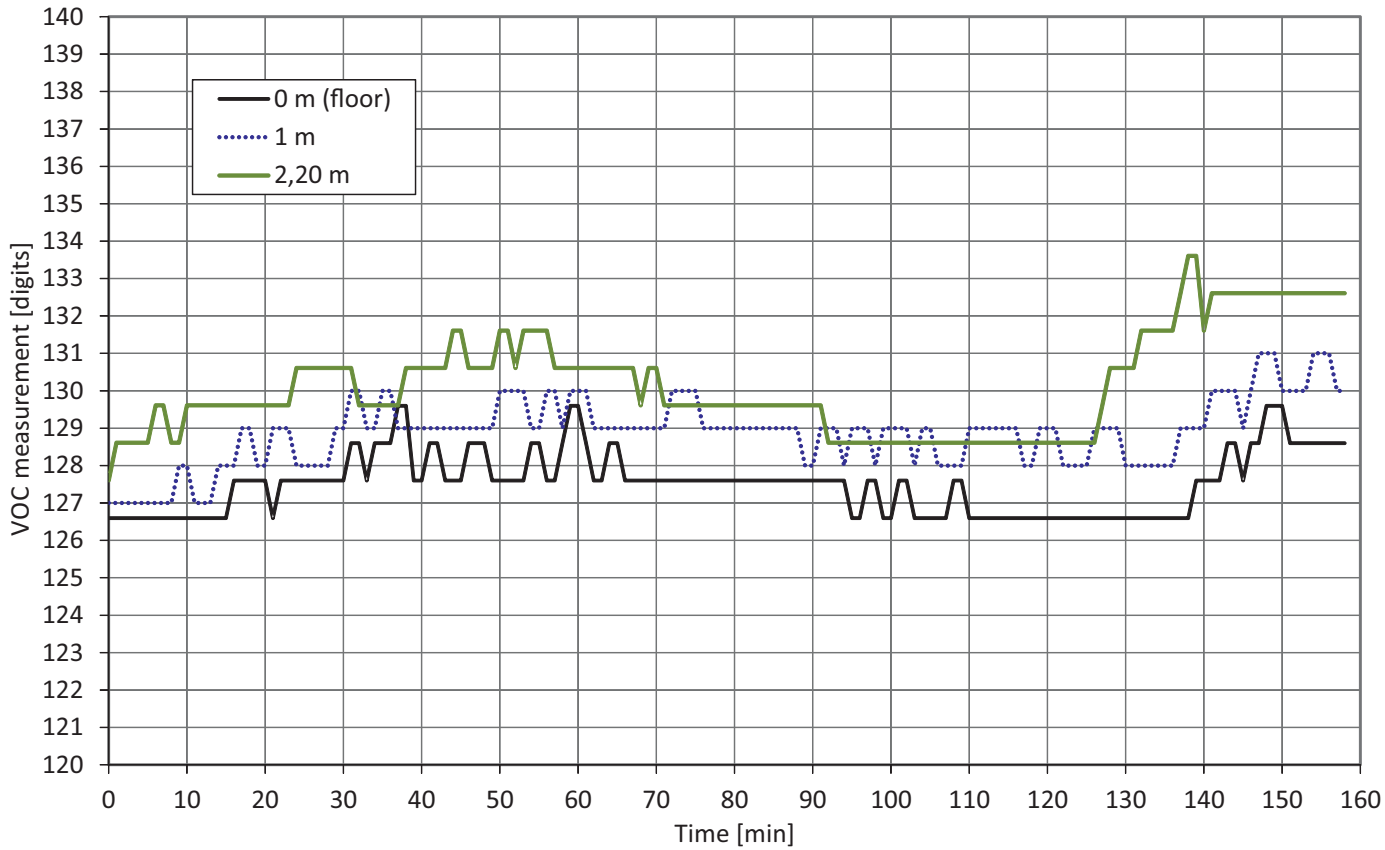

Figure 3. VOC signal at different heights in an office room.

at $1 \mathrm{~m}$ height directly before the measurement of height dependency. For signal dynamics, a higher position of the sensor could be better than a lower one. To detect those VOCs at the level of the head of a person, a medium height seems to be better.

The three sensors had different operation times at the beginning of the 5 week comparison phase. Figure 4 shows the difference in time compared to the sensor at $1 \mathrm{~m}$ height, which had probably the longest operation time until then. After a 5 digit higher signal level at the beginning for sensors 2 and 3, the mean difference decreased in time, but sensor 2 showed a bigger variation. At the end of the 5 weeks, the differences of sensors 2 and 3 remained at 1.7 or 1.1 digits, respectively. That shows that absolute measurement values were very difficult to evaluate in a ventilation control with these sensors. 


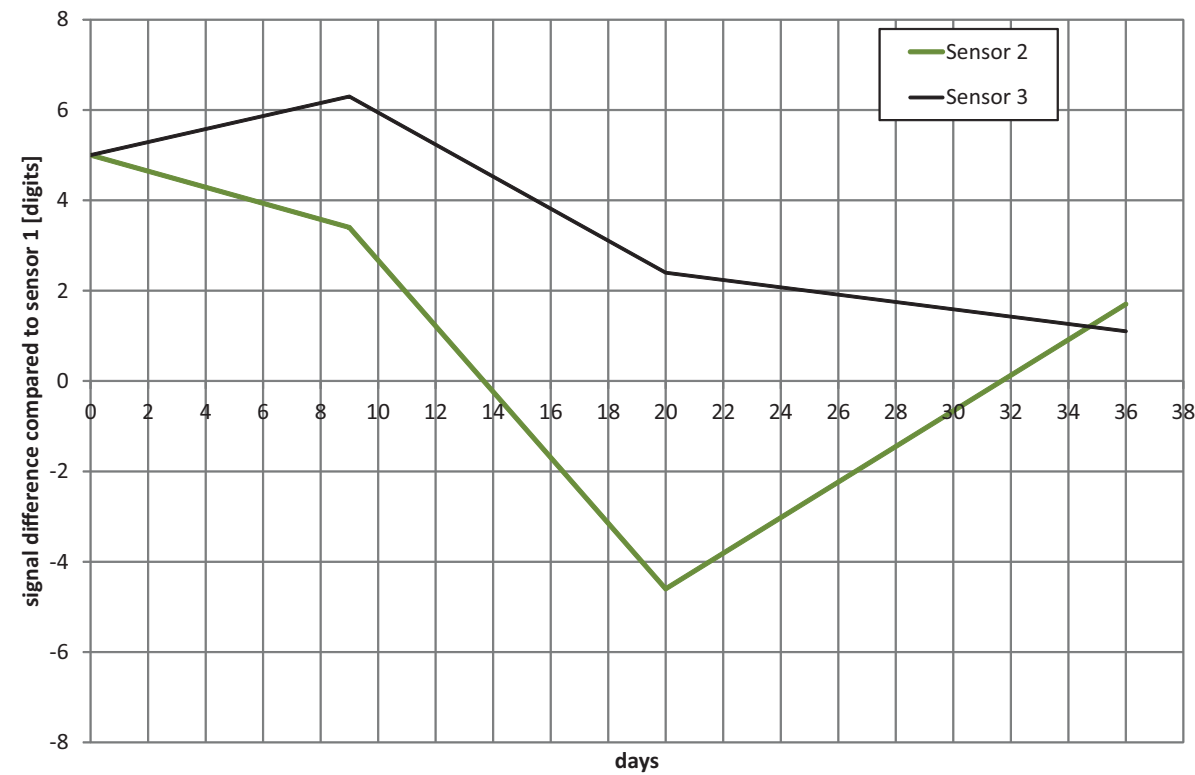

Figure 4. Relative differences between three VOC sensors over a period of 5 weeks.

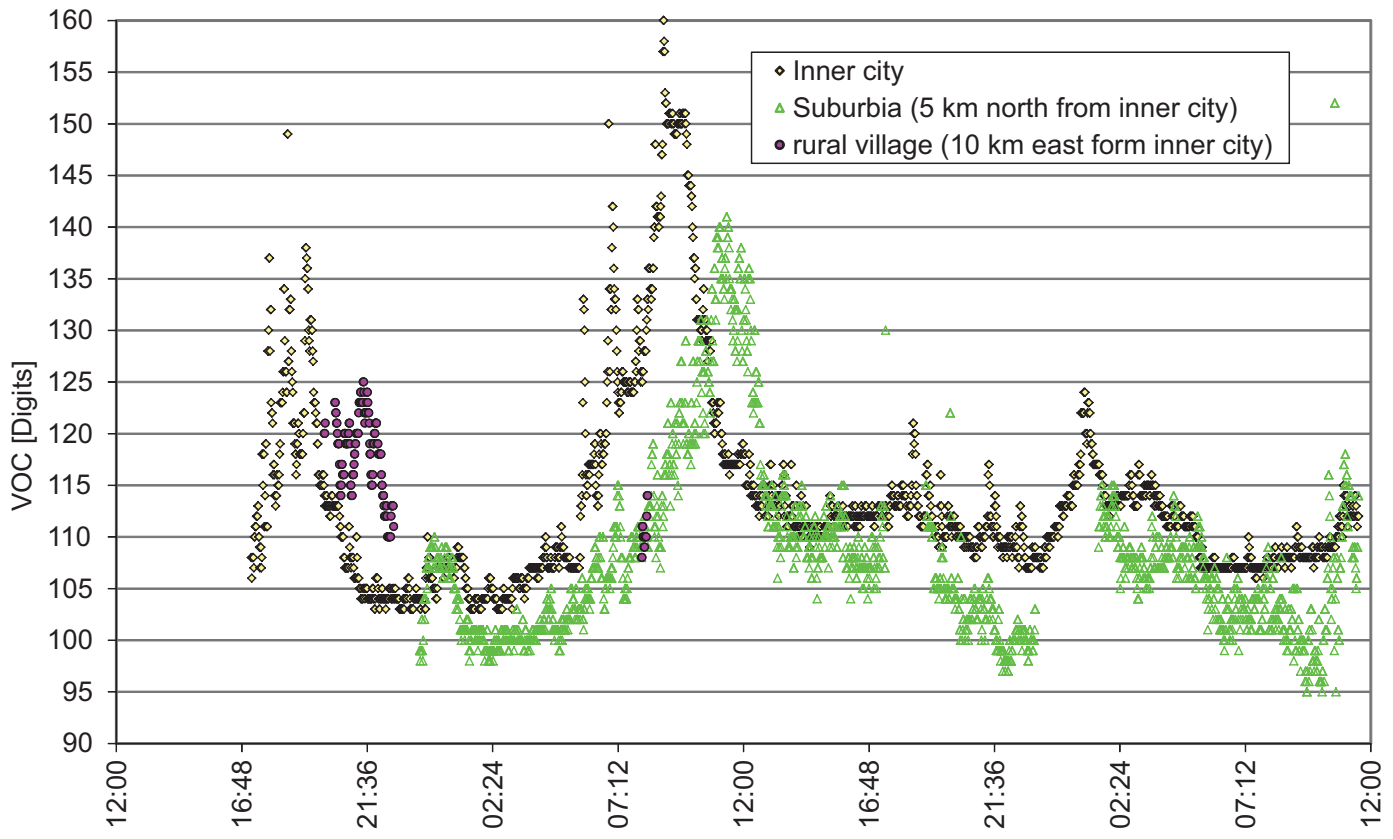

Figure 5. Outside VOC measurements over 2 days at three different locations nearby.

\subsection{Outside air VOC measurement in different regional positions}

To distinguish the variation of the outside air VOC level, the three sensors measured over several days in outside air simultaneously in different places. One sensor was placed at an inner city location, another $5 \mathrm{~km}$ north of the inner city sensor in suburbia, and the third one in a rural area $10 \mathrm{~km}$ east of the inner city. During the time period shown in Fig. 5, the measured VOC level has a very similar trend between the inner city and suburbia, with slightly different signal levels. The values for rural areas are less complete, but have also comparable dynamics. It is important to mention that an intensive slurry odor at the rural measurement could hardly be seen in the measured values. That demonstrates the limitations of the VOC sensors used for the test, because the sensitivity of the human nose is partly higher than those of the electronic sensors. 


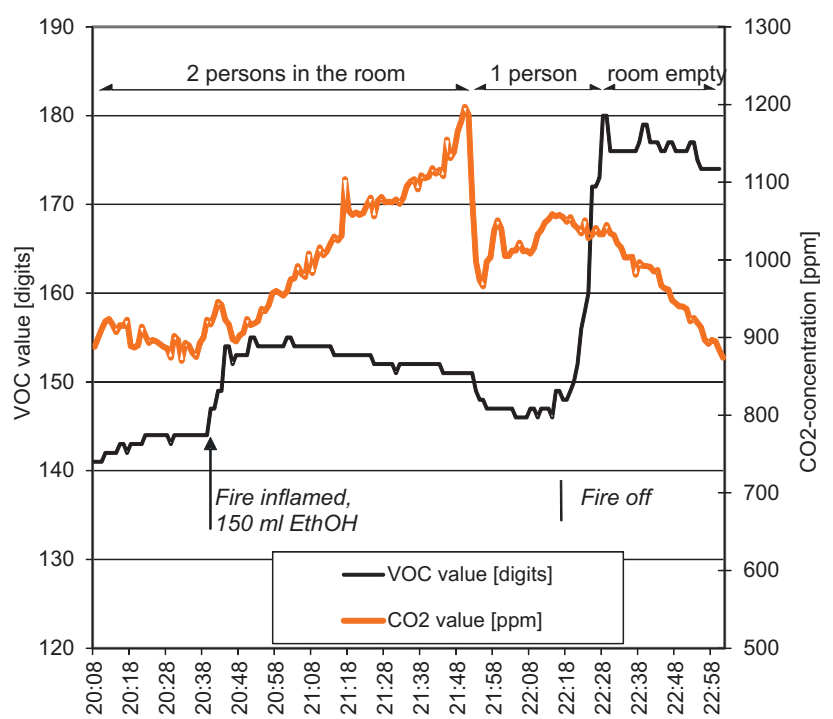

Figure 6. VOC and $\mathrm{CO}_{2}$ measurements with an ethanol oven in a passive house living room with $159 \mathrm{~m}^{3}$ volume.

\subsection{Influence of an ethanol oven on room air quality}

To simulate a high source strength for room air, contamination tests with an ethanol oven in the living room of a passive house with a mechanical ventilation system were done. The room has a living area of $60 \mathrm{~m}^{2}, 2.65 \mathrm{~m}$ height, and the ethanol oven a mean heating power of $600 \mathrm{~W}$. Figure 6 shows the measured VOC and $\mathrm{CO}_{2}$ values in the room. Before inflaming the oven, the $\mathrm{CO}_{2}$ value was around $900 \mathrm{ppm}$ with two people in the room. The VOC level rose slightly. When filling and inflaming the oven, there is a leap in VOC measurement, while $\mathrm{CO}_{2}$ starts to rise constantly. After half of the burning time, one person leaves the room. That could be seen in both values simultaneously, probably because of air mixing in the room. It is interesting that the VOC level rises drastically when the oven expired combustion at the end. The reasons are probably increased evaporation of the remaining ethanol from the hot combustion chamber when the flame expires, or bad burning. In parallel, there is no information about that event in the $\mathrm{CO}_{2}$ measurements. This survey gives hints for the additional advantages using VOC sensors compared to $\mathrm{CO}_{2}$ sensors.

\section{Air quality control}

The results from the preliminary tests influenced the development of the new air quality control (see Fig. 7) that controls the building ventilation system in three steps. Two VOC sensors were used during the field test. The function is as follows.

The VOC values measured in the exhaust air are linearized to correct the logarithmic sensitivity of the sensor. Then, the emission rate of the contaminants is calculated using addi-

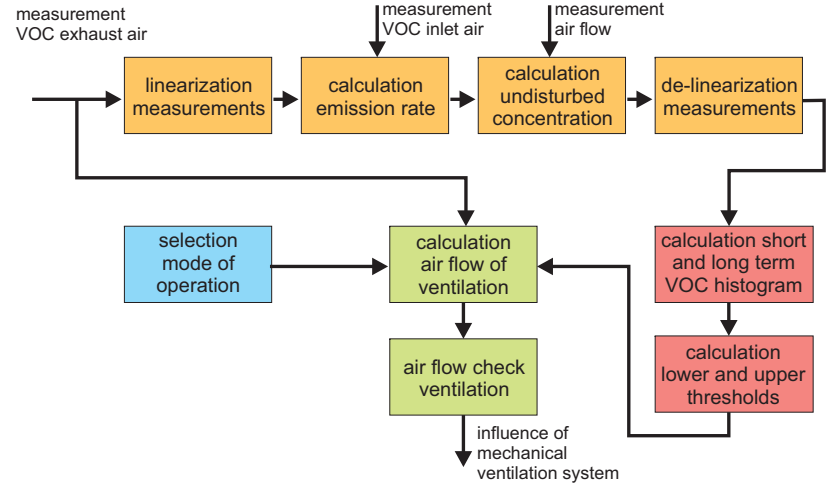

Figure 7. Schematic drawing of the air quality control.

tionally the linearized VOC concentration in the inlet air. With this emission rate and the measured air flow, an undisturbed VOC concentration is calculated for the building without the influence of the changing air flow rates from the air quality control. These concentrations are de-linearized and afterwards two histograms are calculated continuously. One short-term histogram collects the VOC distribution in the building over a period of 14 days and one long-term histogram collects data over 41 days (originally 3 months, which turned out to be too long). The short-term histogram is then used to calculate the threshold for the air quality control, and the long-term histogram for limiting the thresholds against drift because of times of unusual use in the building (e.g., residents are on holiday). The lower and upper thresholds are then calculated as, e.g., the $20 \%$ and $80 \%$ quantiles of the histograms.

For air quality control, the measured VOC value in the exhaust air is compared with the calculated thresholds. If the current VOC value is over the upper threshold, the air flow rate in the building is increased to reduce the contaminants. A VOC value under the lower threshold leads to a reduction in the air flow rate, because the VOC concentration is lower than during normal utilization. Between the lower and upper thresholds, the ventilation system is in normal operation.

This air quality control was implemented with the dasylab data acquisition and control software, collecting all data, calculating the necessary ventilation level and handling the result of the standard ventilation control.

\subsection{Test buildings}

For the field test, four passive houses were chosen, occupied by one family each (normally four persons), situated in three different cities in Germany. All passive houses were built by Schwörer Haus KG, a leading German manufacturer of prefab houses.

The sensors used for the air quality control were placed at the inlet and exhaust air ducts of the ventilation system (Fig. 8). Additionally, in all rooms of the building, VOC sen- 

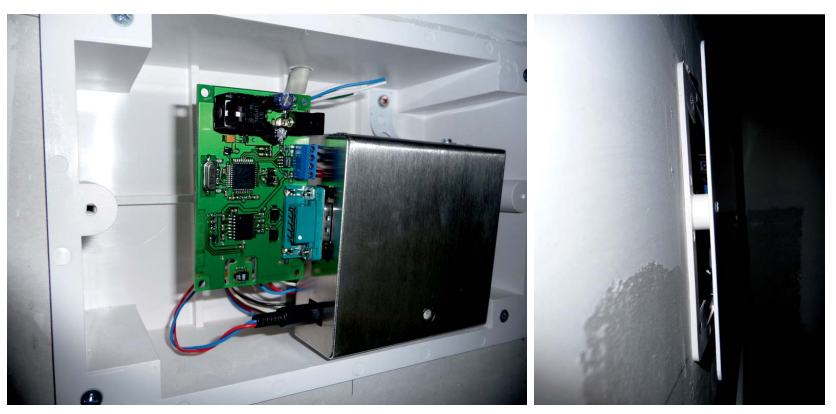

Figure 8. VOC sensors in the rooms were mounted in a box in the wall and are covered by a metal plate fixed $10 \mathrm{~mm}$ in front of the sensor.

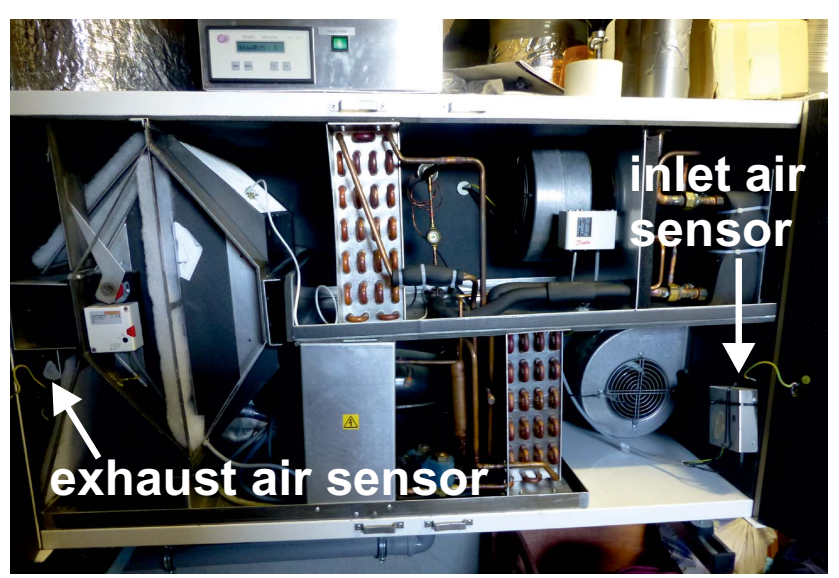

Figure 9. Position of the sensors in the ventilation system.

sors were mounted to compare the concentration measured in the individual room with the concentration in the exhaust air, where air from all rooms is mixed. The room sensors were placed in the walls with a metal plate as coverage $10 \mathrm{~mm}$ in front of the sensor (Fig. 9). Because of the high temperature of the sensor, there is buoyancy-driven permanent thermic ventilation of room air to the sensor. Preliminary tests resulted in no sensitivity of the VOC sensors to the material of the boxes and the metal plate.

\subsection{Results from the field monitoring of the air quality control}

Detailed analyses of the behavior of the air quality control in the four field test passive houses showed a quick reaction to emission peaks in the buildings. The time delay between an increase in VOC concentration and the reaction of the air quality control was about 2-3 min normally (the VOC sensors measured the gas concentration every minute). Also, the short-term (during the day) or long-term (holidays) absence of the residents was detected very well. Additionally, the calculation of the thresholds was not affected by a longer absence of the residents.

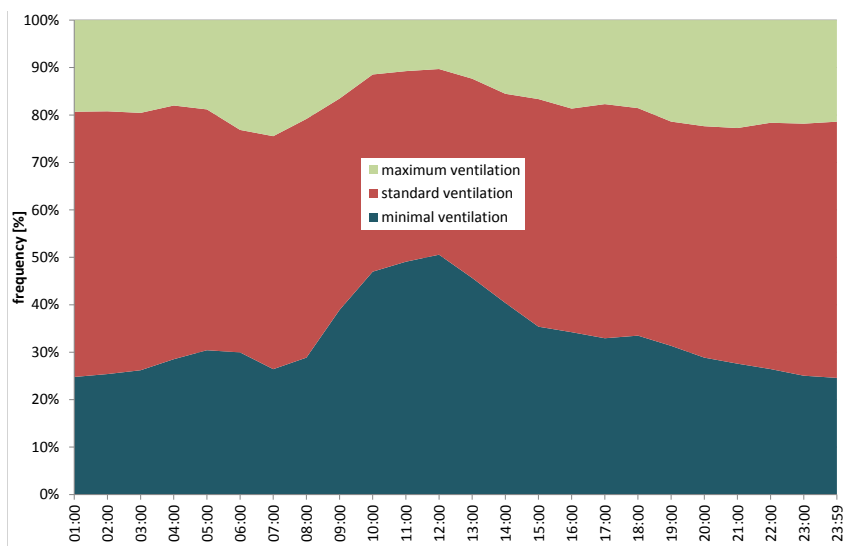

Figure 10. Mean distribution of the three air flow levels in the ventilation system during the day for one building.

Figure 10 shows the mean distribution of the three air flow levels in the ventilation system during the day in one of the test buildings. Standard ventilation is the most frequent mode of operation during the night. Sometimes the ventilation is reduced, for example, when there are no residents in the building, and sometimes the ventilation system is run with the maximum flow rate to reduce VOC levels during the night. During the day, when the residents are absent, the ventilation is reduced to the minimum level, which occurs mainly on working days. This distribution is different in each of the field test buildings because the indoor and outdoor air quality is different, the furnishing is different and, in particular, the residents' daily routines are different.

In Fig. 11, an exemplary day profile of building 4 on 12 September 2011 is shown. Illustrated are the measured VOC concentration in exhaust air, ventilation mode, the lower and upper short-term thresholds and the opening of the front door. Beginning at midnight, the ventilation runs in standard mode interjected by short times of minimal ventilation. Before breakfast, the emissions rise, and so the ventilation has increased to the maximum level. Vice versa, the ventilation is reduced to minimum level after the residents have left the building (which could be seen in the status of the front door). After 1.00 p.m., more people enter the dwelling, and so the ventilation flow rate increased to standard level subsequently.

The users had the ability to increase the air flow rate of the ventilation system by manual input ("party button") if needed. The assessment of the situations, when the residents pressed the button for maximum air flow, showed that in most situations the air quality control had already increased the air flow to the maximum value. That means that air quality control and user sense worked very similarly.

The air quality control resulted in a slightly lower ventilation flow rate in mean than in standard operation mode (1-6\% less). But, the reduction leads only to a low decrease in heat and auxiliary energy consumption because of the heat 


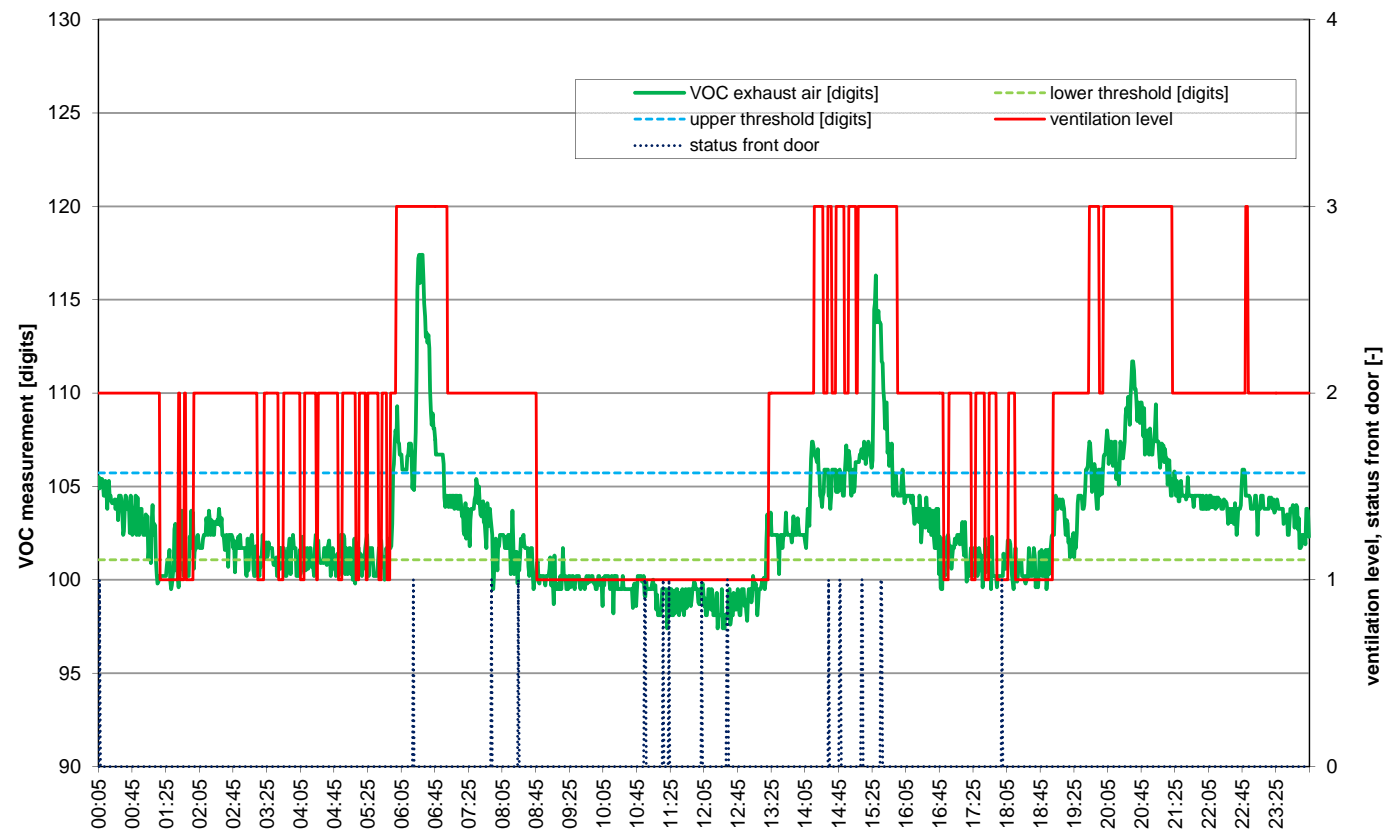

Figure 11. Example daily profile of VOC concentration in exhaust air, ventilation mode.

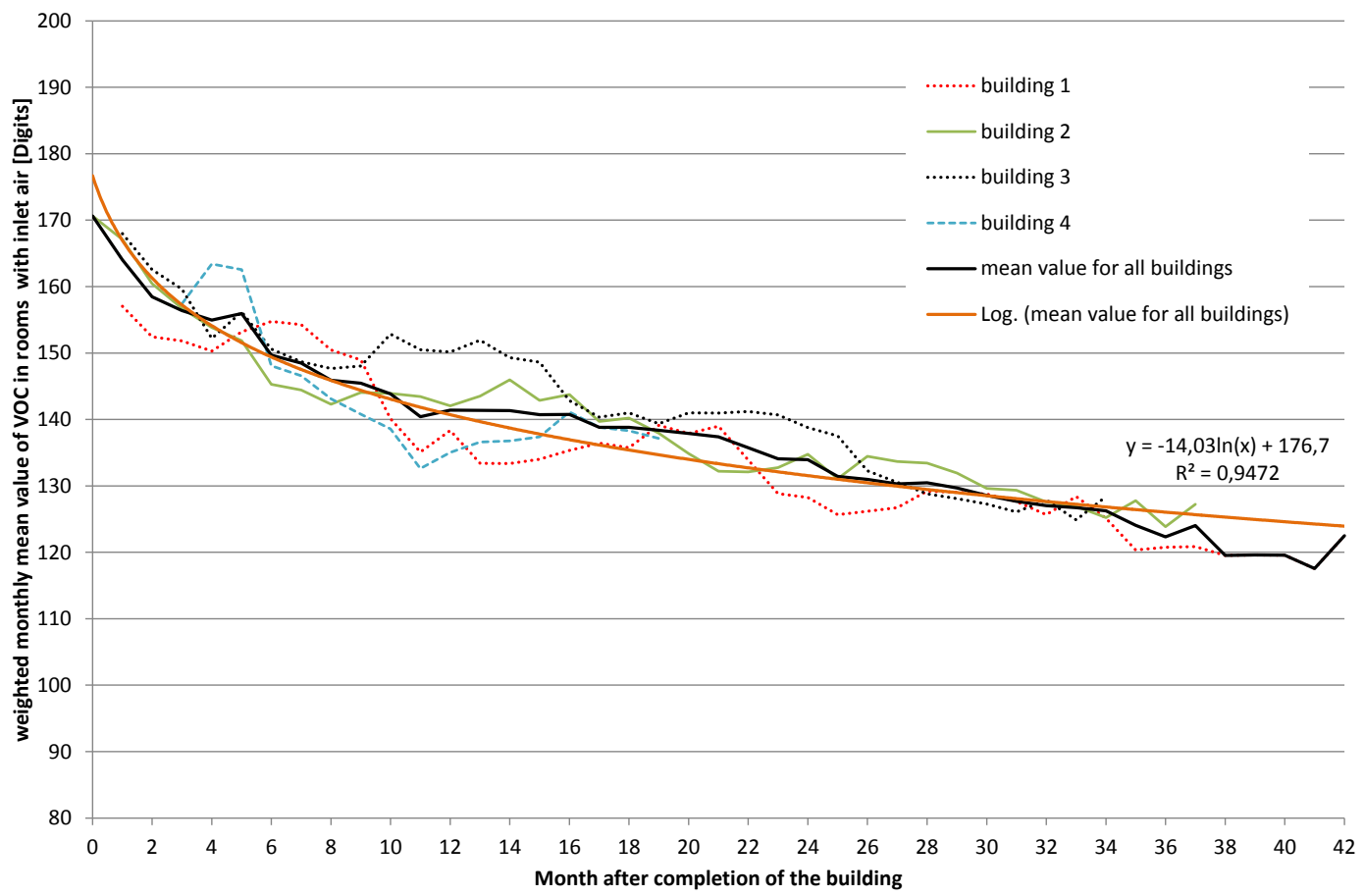

Figure 12. Weighted mean VOC concentration in the four test buildings in time elapsed after move-in. 


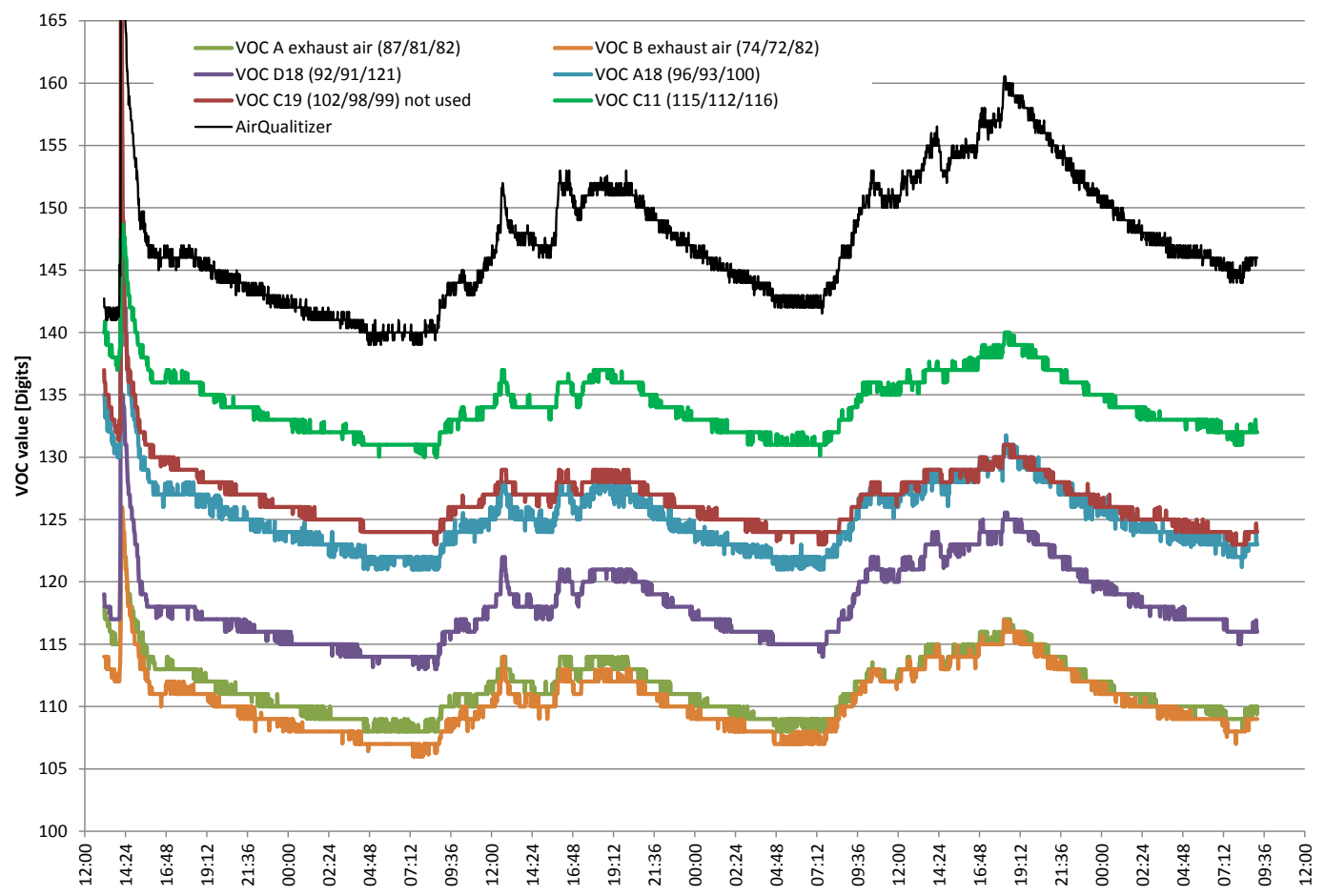

Figure 13. Signal dynamics of six used VOC sensors from the field test and one AirQualitizer (AirQualitizer, 2012) in an office room.

recovery and the highly efficient fans. In buildings like passive houses, the advantage of air quality control focuses on an increase in comfort for the residents. For the use in other buildings, see Sect. 5 .

\section{Experiences with the VOC sensors in long-term use and comparison with $\mathrm{CO}_{2}$ sensors}

\subsection{Long-term development of VOC level}

Measuring the VOC concentration in the exhaust air yielded a good mean VOC concentration in the building, but with an emphasis on the exhaust air rooms (kitchen, bathroom, WC). The measured VOC concentration decreased after the mounting of the building during the first months. It is not known till when the changing of the calibration of the sensors (see below) had a significant influence on the measurements (Fig. 12).

The measured VOC concentrations in the inlet air showed a significant dependency on the air humidity, rapidly changing in the test buildings because of the inlet air heating with a heat pump. During the year, a fluctuation of the fresh air VOC concentration was detected, probably resulting from the changing humidity of the fresh air. The conclusion drawn from these results is that there was a non-negligible influence of air humidity on the measured VOC level.

\subsection{Recalibration results}

All VOC sensors were recalibrated after the end of the field test to determine the drift between delivery and end of the monitoring phase (span of time about 4 years). The calibration gas was carbon monoxide (CO). The VOC sensors mounted in the inlet air had a deviation from the original calibration, but showed similar characteristics. The sensors mounted in the exhaust air and in all rooms had hardly any sensitivity to the gas CO left. Anyway, the sensors had a nameable signal dynamics in room air, so the air quality control could still influence the flow rate of the ventilation system. Figure 13 shows a comparison of six VOC sensors from the field test and one new AirQualitizer (a very similar sensor by AL-KO Therm GmbH, Jettingen-Scheppach, Germany) during 3 days in a normal office room. The signal level is different, but the characteristic signal dynamics is still there, even if the individual sensor has no notable reaction to the calibration gas $\mathrm{CO}$ (values in brackets for 0,5 and $20 \mathrm{ppm}$ $\mathrm{CO}$ during the recalibration).

The air quality control appeared to be robust against sensor drift because of the continuous recalculation of the thresholds.

The operation time of the 43 VOC sensors added up to $1200000 \mathrm{~h}$ of operation during the field test without an electrical failure of a sensor. The electrical stability seems to be very good. In inlet and exhaust air, additional VOC sensors packed in an M18 screw thread were mounted. They were used parallel to the ones described above, but did not have 


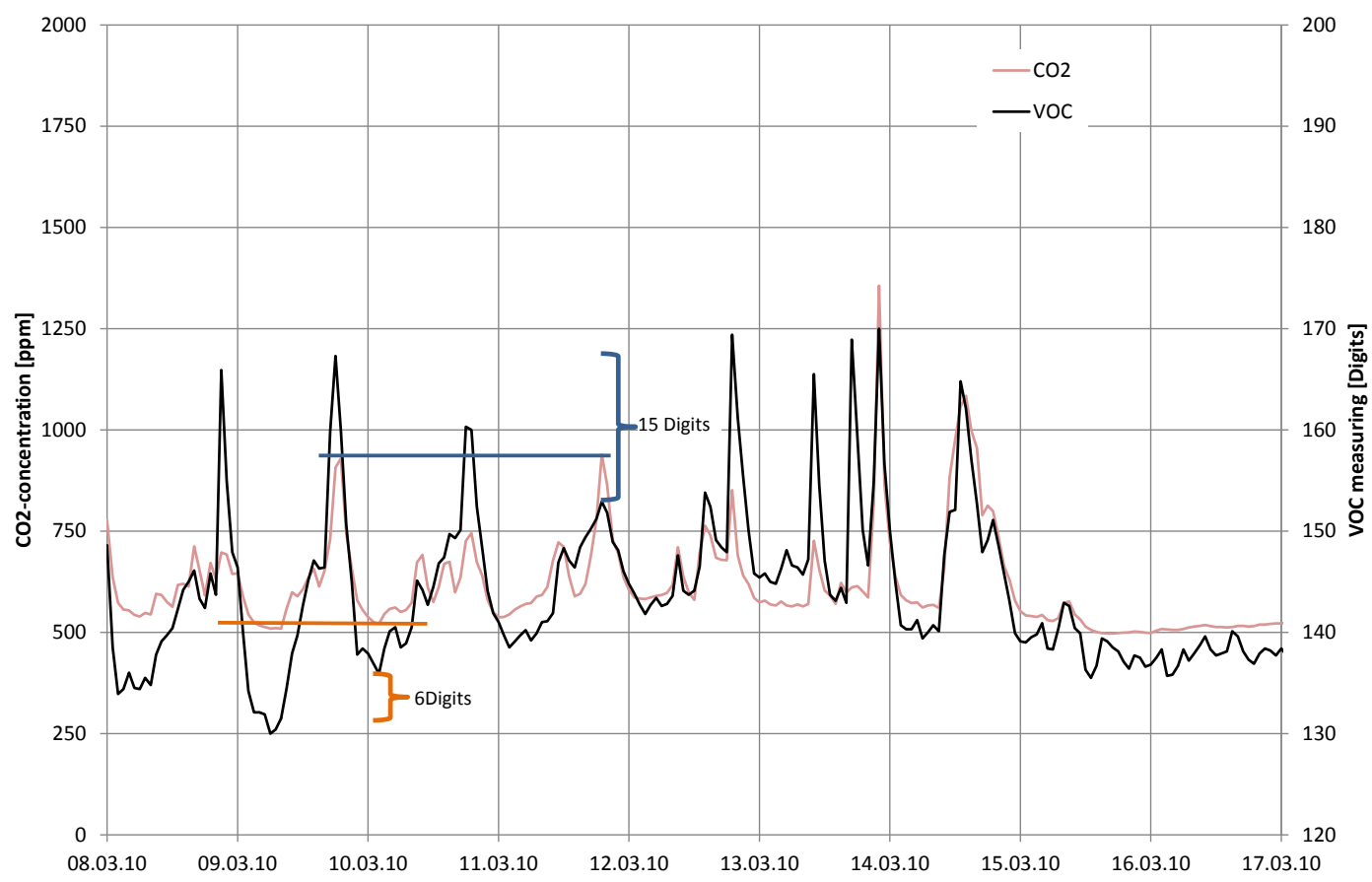

Figure 14. VOC and $\mathrm{CO}_{2}$ measurements in the living room of one test building over 1 week.

their stability. Of those mounted in the inlet air, all broke after a while. Maybe, the temperature leap while heating the inlet air led to electrical problems.

In principle, an air quality control could also be constructed with $\mathrm{CO}_{2}$ sensors. A comparison between the measured dynamics of the $\mathrm{VOC}$ sensors and $\mathrm{CO}_{2}$ sensors mounted parallel in the rooms of one building showed some similar signals resulting from peoples' activities in the building (e.g., during the night time). Other VOC sources like emissions from the building materials or the furniture could not be detected with $\mathrm{CO}_{2}$ sensors. This is the reason why VOC sensors have some advantages for use in air quality control.

Figure 14 shows the comparison of measured $\mathrm{CO}_{2}$ and VOC values during 1 week. Some peaks are very similar at the $\mathrm{CO}_{2}$ and VOC sensors, but others with the same $\mathrm{CO}_{2}$ measurement show wide differences in VOC value. Odors especially could not be detected with $\mathrm{CO}_{2}$ sensors.

\section{User feedback}

Introducing new techniques in buildings could lead to user discontentment when their needs are not considered. For that reason, user interviews had been held during the monitoring phase with the residents of the buildings. In addition to the users' global contentment with their passive houses, questions about their contentment with indoor climate, ventilation systems and air quality resulting from the new air quality control had been asked.
The residents said that the air quality was good even after a longer absence of people in the building and that they could not distinguish between indoor and outdoor air quality. Odors, for example in the kitchen, could be removed quickly. Smaller problems with air quality in individual rooms were solved by correcting the air flow rates, which did not match the planned values. The noise from the changing ventilation levels was low and not disturbing.

\section{Conclusion and outlook}

In highly efficient buildings, the air quality control leads to improvements in buildings' air quality, but there are only a few possibilities to reduce energy consumption because of the existing heat recovery. In contrast, energy efficiency could be increased significantly when implementing the air quality control in an exhaust air ventilation system (with no inlet air ducts and no heat recovery), e.g., for retrofitted buildings, to reduce costs and work in rented flats. By means of the automatic detection of air quality, the air flow rate in the flat or building could be adapted to the actual demand, which reduces ventilation heat energy losses and saves nameable energy. With this combination, low refurbishing costs could be combined with low heating costs. This application could support the energy transition in the building sector.

Nevertheless, long-term stability of the VOC sensors is an important issue for industrial use in buildings, where usage times of 10-20 years are expected. Newer generations of VOC sensors could possibly match these requirements and 
be used for building air quality control for ventilation systems.

Acknowledgements. The author thanks the German ministry for economics and technology for funding the research project (funding code 0327 398A). Additional thanks go to the project partners: the former ETR-Electronic in Dortmund, now AL-KO Therm $\mathrm{GmbH}$, who delivered the sensors, developed an interface for a bus system and did the recalibration, as well as Schwörer Haus KG, who provided the integration of the control into the ventilation and heating system of the field test buildings, and engineering consultant ebök GbR in Tübingen, who assisted in topics of changing the pressure balance in the building and did measurements of noise and air tightness in the test buildings. Special thanks go to Jens Knissel, University of Kassel, Germany, who initiated and led the project at the Institute for Housing and the Environment (IWU) in Darmstadt for a long time.

Edited by: K.-D. Sommer

Reviewed by: two anonymous referees

\section{References}

FIA e.V.: LUQUASII Triplesensor, Abschlussbericht, ISBN 3938210-12-5, FIA e.V., Bietigheim-Bissingen, Germany, 2005.

Fisk, W. J. and de Almeida, A. T.: Sensor-based demand-controlled ventilation: a review, Energ. Buildings, 29, 35-45, 1998.

Großklos, M., Ebel, W., and Knissel, J.: Entwicklung energieeffizienter Komfortlüftungsanlagen, Technical Report 1: Einsatz des LuQaS-Triple-Sensors zur luftqualitätsgeführten Volumenstromregelung von mechanischen Lüftungsanlagen in Wohngebäuden, Institut Wohnen und Umwelt (IWU), Darmstadt, Germany, 2011.

Großklos, M. and Hacke, U.: Entwicklung energieeffizienter Komfortlüftungsanlagen, Technical Report 3: Endbericht und Dokumentation der Feldphase, Institut Wohnen und Umwelt (IWU), Darmstadt, Germany, 2012.

Knissel, J., Großklos, M., and Werner, J.: Entwicklung energieeffizienter Komfortlüftungsanlagen, Technical Report 2: Theoretische Untersuchungen zur Druckdifferenz-Methode, Institut Wohnen und Umwelt (IWU), Darmstadt, Germany, 2011.

Kopiske, G., Imann, C., Clausnitzer, K.-H., Simers, U., and Llamas, M.: Wissenschaftliche Begleitung sowie Verifizierung einer Lüftungsampel für den Einsatz im Mietwohnungsbau und in Schulen, UTEC, Bremer Energieinstitut und Bremer Umweltinstitut, Bremen, Germany, 2004. 